\title{
Educating the Aerospace Engineer of 2016
}

\author{
Narayanan Komerath, Mark D. Maughmer \\ Georgia Institute of Technology / The Pennsylvania State University
}

\begin{abstract}
The U.S. aerospace industry is changing rapidly, from vertically integrated development and manufacturing to "large system integration" as their main business. Driven by global competition, the new capabilities also enable the realization of some grand dreams of humanity. This paper lays out two scenarios and argues that leadership will reach or exceed the optimistic scenario. This scenario is used to gauge implications for engineering education. The needs for depth and breadth must be balanced. Skills in developing business cases, teamwork and crossdisciplinary learning must be addressed. Emphasis must shift from measuring "teaching" to "learning", "applying" and "innovating". Examples of modern "best-practices" are used to lay out some of the essential elements for the new aerospace engineering education.
\end{abstract}

\section{Introduction}

Curricular innovations started today will influence corporate leadership when the Classes of $2005-2009$ are some ten years beyond graduation. We use present assumptions to develop two example scenarios aimed to straddle the reality of 2016. This paper was inspired by our experience this summer as Boeing A.D. Welliver Fellows, when we were able to compare perspectives from academia, U.S. industry and the global marketplace. The paper is condensed from one of the reports that we submitted to Boeing.

Around the time that our summer fellowships ended, the National Academy of Engineering released their report on The Ingenious Engineer of 2020. ${ }^{1}$ The NAE also used scenarios on a grand scale. One related to the effects of continued automation and commercialized bionanotechnology on a corporate lifestyle. One visualized a natural disaster - a tsunami caused by an asteroid impact, devastating the Pacific Northwest - brought home all too vividly by the catastrophe in Asia at the end of 2004. A third envisaged global conflict with weapons of mass destruction. Our project is much less ambitious in scope, and is focused on how aerospace engineering undergraduates must be educated starting this year. We note that the aerospace enterprise has consistently brought a large trade surplus to the US for several decades and has generally managed to lead innovation through the past century.

Recent aerospace industry changes appear to be driven by an imperative for cost cutting - a process described recently by airline employee representatives as a "race to the bottom". This process, followed to its extremes, results in a very negative scenario - albeit one that is logical based on passive reaction to dynamic constraints. On the other hand, current trends also open up exciting opportunities to move to an entirely new level where very large, global projects become 
feasible in a vastly expanded aerospace economy. The changes in industry and academia needed to realize this optimistic scenario are considered.

As aerospace engineers and educators, we try to imagine the answers to the following: Who will produce the aerospace vehicles of 2020? 2050? How? Who will the users be, and how will these vehicles be used? What types of vehicles will be produced? How do we get there from here? Someone will imagine these vehicles, articulate their need to meet certain demands or to create new markets, develop conceptual designs, design the vehicles, produce and fly them. We try to reason out the requirements and the path to this stage. We first try to describe the market and its needs, in order to guide the development of requirements and objectives, and then suggest solutions. Today's AE senior can expect to influence vehicle design projects in 2015, ten years out of school. We picked 2016 as a target year - when the Boeing Company turns 100.

We make the following assumptions about 2016. Gasoline prices show no sign of easing, and predictions of "Peak Oil" arriving ${ }^{2}$ around 2008 appear if anything to be optimistic - it may already be here. Thus we project that gasoline will cost in the range of $\$ 8 /$ gal, and jet fuel costs at least 4 times what it does today. Most automobiles may operate on hybrid electric engines fed using natural gas or hydrogen fuel cells. A hydrogen economy may arrive quicker than we thought. Current gasoline prices in the U.S. exceed the DOE target price of $\$ 2$ for delivered hydrogen, ${ }^{3}$ and the current gasoline prices in Europe and Asia (\$3.60) exceed GE's current \$3.50 estimate of a feasible delivered cost in U.S. cities for hydrogen. People will want to travel. The Space Program will have become dominantly commercial, either through expansion of the commercial market, or through attrition and collapse of public support for a weak and uninspiring civil space program.

\section{Scenario 1: Managing Contraction}

The first of our scenarios is a linear extrapolation of current trends. It shows the American aerospace industry transitioning, under intense global competition, from integrated vehicle developer-manufacturers into large system architects, analysts and integrators - a process that is well underway. Commercial aircraft production moves away from US shores, driven both by manufacturing cost and by the need to get participation as funding partners (and locked-in customers) from foreign national carriers. In the middle term, US-located plants continue to perform the R\&D, design and final assembly. In the longer term, most manufacturing appears headed for outsourcing. The role of lead systems integrator (LSI) is profitable as leaders use tools from past R\&D, with the experience base of veterans from manufacturing. The LSI cuts risk and improves returns by keeping hardware development at arms' length ${ }^{4}$. As the new manufacturers develop experience, skills and tools, it appears inevitable that they too will aspire to become LSIs. When this occurs, profit margins will again drop in competition. US corporations will attempt to exploit esoteric markets, leveraging access to government contracts.

This is today's "globalization" scenario that appears equally ominous for American industry and engineering education. As successively higher levels of engineering endeavor are outsourced to entities located away from U.S. shores, it appears inevitable that demand for U.S. engineering graduates will also drop. Large engineering education programs in the US would be irrelevant since manufacturing in, say, Japan, is probably best accomplished by engineers trained in Japanese educational institutions. 
The tussle in the commercial aircraft market is instructive. Consolidation since the end of the Cold War has formed two dominant commercial aircraft manufacturers: Boeing and Airbus. Russian, Canadian and Brazilian manufacturers occupy niche markets. Boeing, being a publictraded corporation, must base its project decisions upon return on investment to shareholders, at a higher priority than maintaining aerospace dominance. Airbus on the other hand makes no secret of the fact that employing engineers and advancing European aerospace interests are central to its mission. Thus it can justify even a very small profit margin on the grounds that it provides high-value technology jobs. Global economic contractions have driven down the demand for airliners well below supply capabilities for the immediate future. In this environment, profit margins are shaved even lower. The entry of lower-cost manufacturers, possibly Japan or China, in the lead system integrator role is not an immediate fear; however, it is a legitimate concern over the 15 to 20 year life cycle required to make profits on a new airliner project. In the commercial space launch market, where the demand for new satellites has dropped to dismal levels, launch cost may come down. Private space launch companies may offer suborbital space rides, but since such rides today achieve only about $10 \%$ of the energy required for Earth orbit, they are some time away from revolutionizing orbital launch capability.

Industry strategists project an evolution of the engineer's job into that of the knowledge worker. Geographical location however, is almost irrelevant to such work. Knowledge worker jobs are even easier to outsource than manufacturing jobs, and may in fact be distributed all over the globe for each project. Thus, merely "moving up the value chain" to the top of the knowledge pyramid does not lead to an optimistic scenario for the U.S. engineering profession or academia without massive growth in demand for aerospace products.

Much recent attention has been devoted to this gloomy scenario. ${ }^{5,6,7,8,9}$ Mercer $^{5}$ notes that the jobs being advertised by Administration officials as signs of economic recovery are far from being good replacements of engineering / technology careers. She warns of the disastrous effects of discouraging American youngsters with aptitude in the mathematical sciences by telling them that the "hot' occupations of the future do not require such aptitudes. Economist Paul Craig Roberts is quoted as saying that "only labor involved in non-traded goods and services is safe from foreign substitution." This is a replay of what happened to engineers and factory workers employed in many nations at the beginning of the globalization process, when protected markets were opened to the flow of manufactured goods from automated plants in developed countries. In another article, ${ }^{6}$ Mercer wonders whether the U.S. has become less innovative.

Miller $^{8}$ sees the projected shift of 2 to 3 million present "white-collar" jobs overseas by 2015 as being part of the evolution of technology. He points to the fact that the special strength of the U.S. is innovation, and so as technologies mature, it is expected that they will shift elsewhere as the US takes on new challenges. Williams ${ }^{9}$ surveys the literature on technology and engineering in the American experience. He traces the vast and pervasive impact of engineering on all aspects of American life and history. A glance at the huge variety of engineering innovations ${ }^{10}$ of the past summarizes how society and our outlook have been transformed.

\section{A nuance to the tradition of innovation}

The gloomier perspectives appear to assume that overall demand will remain flat or drop, so that competition focuses on cost cutting. Agreement however, appears to be emerging that the traditional American advantage has been in leading innovation. We would add a nuance - that the real American strength has been in bringing new concepts to reality on a grand scale. This 
route also opens vast new markets and opportunities to create new wealth. It thus breaks out of the zero-sum game and the "race to the bottom" characteristics of strategies that are limited to cost cutting. One grave danger is that the traditional enthusiasm to fund innovation, which comes out of sustained long-term research and development, may be slipping. Segal ${ }^{11}$ points out that the 50 -year economic "edge" maintained by the United States may be in danger as other nations pour resources into research and development at a faster rate than the U.S.

\section{Scenario 2: Leading Innovation}

This scenario envisages a breakout, creating new markets. We look at opportunities for leadership in two vast areas: air transportation and building a space economy. There is currently a divergence of strategies between Airbus Industrie's larger hub-to-hub airliners such as the A380, and Boeing's emphasis on long-range medium-sized point-to-point transport exemplified by the 7E7. The hub-to-hub strategy emphasizes fuel economy, at some cost in passenger convenience. The point-to-point strategy can potentially open up new airports to long-distance flights, and create a demand for increased flight speed. In this sense it bets on the economic development of mid-sized cities around the world. This has the potential to reopen the prospects of supersonic travel, perhaps with an interim generation of supersonic business jets.

The rise in fuel prices is likely to accelerate the introduction of new fuel solutions. In the longer term, the probable switch of the road transportation industry to hydrogen fuel would bring down costs and encourage use of hydrogen fuel on airliners. The unique status of aviation fuel which is priced far lower than automobile fuel, may disappear as the road industry switches away from fossil fuels, and as hydrogen costs come down. This would drive aircraft design to different configurations, because of the volume requirements and volatility of liquid hydrogen.

The decision to return to the Moon, announced in 2004, offers an unprecedented opportunity for concepts in extraterrestrial resource exploitation - such as extraction of oxygen on the Moon. Expertise in large system architecture potentially enables U.S. companies to provide a unique capability. This is to be the architects of the Space-based economic enterprise. Even more than the airliner industry, projects to build large-scale Space infrastructure may be expected to require international collaboration; however the bulk of the expertise will remain in the U.S. as long as we maintain leadership in Space endeavors. Examples of large projects are a lunar base, solarelectric power plants, oxygen plants, electromagnetic launchers, orbiting fueling stations and orbit transfer vehicles. Collins ${ }^{12}$ makes two bold predictions regarding the importance of space endeavors to the civil engineering profession: "Prediction 1: "Popular space travel will do for the 21st century what aviation did for the 20th century. Passenger space travel will grow from zero to more than $\$ 1$ trillion/year, creating new employment for tens of millions of people, and profoundly changing our daily life on Earth". Prediction 2: "Within little more than 10 years, space will be the front line of the hotel industry. Space hotels will be a focus of media interest, and they will show rapid development as they compete to attract guests with more and more advanced facilities exploiting the unique environment of space." We note this without comment except that enthusiasm for Space endeavor is not limited to the aerospace industry.

Clearly, the above scenario involves large-scale changes and a large expansion of the aerospace marketplace. The traditional assumption ${ }^{13}$ has been that the induction of supersonic transports would take away market share from the U.S. transonic airliner business. This is rebutted by the 
rapid growth of demand for air transportation in the Eastern Hemisphere, and the fact that the transonic large airliner market is increasingly dominated by non-U.S. entities. The introduction of supersonic point-to-point travel options may drive a large surge in demand for long distance air travel, as older, wealthier residents find the travel times to be short enough to be worth the price, effort and health risks. In the Space arena, a determined multinational effort to build significant infrastructure in orbit and on the Moon would enable a vast array of business concepts dealing with secondary services between the primary projects.

\section{Desired Attributes}

We believe that industry leadership will select a path that is at least as smart as the more optimistic scenario that we can lay out for our students today, and hence there is every reason for optimism. The NAE report ${ }^{1}$ summarizes the issues thus: "The next several decades will offer more opportunities for engineers, with exciting possibilities expected from nanotechnology, information technology, and bioengineering. ... Other engineering applications, such as transgenic food, technologies that affect personal privacy, and nuclear technologies, raise complex social and ethical challenges. Future engineers must be prepared to help the public consider and resolve these dilemmas. Challenges will also arise from new global competition, requiring thoughtful and concerted action if engineering in the United States is to retain its vibrancy and strength." Table 1 compares the NAE's summary description of the "Ingenious Engineer of 2020" with the Boeing-generated "Desired Attributes of an Engineer" ${ }^{14}$ from the mid-1990s. There are some differences. Industry's move towards "large systems integration" is only peripherally reflected in the NAE's list. The "good understanding of design and manufacturing processes" and "profound understanding of the importance of teamwork" important to industry are absent or muted on the NAE's list.

Table 1: Comparison between the Attributes of the Engineer from the mid-90s, and the 2004 NAE vision of the attributes of the Engineer of 2020

\begin{tabular}{|c|c|}
\hline Boeing: Desired Attributes of the Engineer, ${ }^{15}$ & $\mathrm{NAE}^{1}$ Attributes of the Engineer of 2020 \\
\hline $\begin{array}{l}\text { 1. A good understanding of engineering science } \\
\text { fundamentals: Mathematics (including statistics), Physical } \\
\text { and life sciences, and Information technology (far more } \\
\text { than "computer literacy") } \\
\text { 2. A good understanding of design and manufacturing } \\
\text { processes. (i.e., understands engineering) } \\
\text { 3. A multi-disciplinary, systems perspective. } \\
\text { 4. A basic understanding of the context in which engineering } \\
\text { is practiced: Economics (including business practices), } \\
\text { history, the environment, customer and societal needs } \\
\text { 5. Good communication skills: Written, oral, graphic and } \\
\text { listening } \\
\text { 6. High ethical standards. } \\
\text { 7. An ability to think both critically and creatively - } \\
\text { independently and cooperatively. } \\
\text { 8. Flexibility. The ability and self-confidence to adapt to } \\
\text { rapid or major change. } \\
\text { 9. Curiosity and a desire to learn for life. } \\
\text { 10. A profound understanding of the importance of teamwork. }\end{array}$ & $\begin{array}{l}\text { 1. Strong Analytical Skills } \\
\text { 2. Practical Ingenuity } \\
\text { 3. Creativity } \\
\text { 4. Good communication skills } \\
\text { 5. Mastery of business and management } \\
\text { principles } \\
\text { 6. Mastery of principles of leadership } \\
\text { 7. High ethical standards } \\
\text { 8. Strong sense of professionalism } \\
\text { 9. Dynamism, resilience, agility, flexibility } \\
\text { 10. Lifelong learner. } \\
\text { In summary, s (he) "will aspire to have the } \\
\text { ingenuity of Lillian Gilreth, the problem-solving } \\
\text { capabilities of Gordon Moore, the scientific } \\
\text { insight of Albert Einstein, the creativity of Pablo } \\
\text { Picasso, the determination of the Wright } \\
\text { Brothers, the leadership abilities of Bill Gates, } \\
\text { the conscience of Eleanor Roosevelt, the vision of } \\
\text { Martin Luther King, and the curiosity and wonder } \\
\text { of our grandchildren". }\end{array}$ \\
\hline
\end{tabular}


The NAE list mandates increase in breadth of engineering education, concurrent with increased depth to deal with the new technologies that it notes as fields of promise. The list emphasizes aptitude for leadership across professions, including roles such as educating policy debate. The educator's challenge is to translate the above guidance into practical steps in the curriculum. There is debate among NAE experts on the need to push the first engineering degree out to a fifth year; however, barring this development, one must assume that the time available to impart the new, broader, deeper education to the 18-year-olds of 2016 will be the same as that available to educate 18-year-olds now.

Clearly, all of the above cannot be "taught" in courses within any reasonable time. It has to be learnt by students. The learning will occur from many sources, of which classroom instruction is at best the most important. The change from measuring what we "teach" to what we manage to get learners to learn, is crucial, and implementing it will be a tough challenge.

Barke et al. ${ }^{16}$ has argued for a convergence of the engineering and liberal arts curricula, because it no longer makes sense to make these mutually exclusive. We do not recommend that route entirely, because the engineer is still required to have substantial depth and quantitative skills that take a long time to impart through any present mode of instruction. Felder et al. ${ }^{17}$ detailed

Table 2: "Teaching Methods that Work" Felder et al. ${ }^{17}$
1. Formulate and publish clear instructional objectives
2. Establish relevance of course material and teach
inductively
3. Balance concrete and abstract information in every
course
4. Promote active learning in the classroom
5. Use cooperative learning
6. Give challenging but fair tests
7. Convey a sense of concern about the students pedagogical strategies that worked in chemical engineering education, seven of which are listed in Table 2. These strategies relate to the predominance of learners of a given learner style. Our experience has shown that caution must be used that the adoption of the "best" techniques does not marginalize learners of other types.

\section{Changes to the Aerospace Engineering Curriculum}

The apparent similarity between the lists in Table 1 masks the large changes that have occurred in the past two decades in undergraduate engineering education. While some changes have been institutionalized through the ABET accreditation process, a wealth of research results remains untapped except in a few places. Below we list suggested thrust areas based on our own experience: depth of understanding, learning by iteration, learning across disciplines, knowledge retention, distillation and lateral application.

\section{Freshman Conceptual Design Follows “RD \&O” Systems Thinking}

Various forms of freshman design experiences were tried out in the 1990s in American universities. At Georgia Tech, the freshman "Design-Centered Introduction" to Aerospace Engineering uses ${ }^{18}$ the conceptual design process of flight vehicles to introduce the various disciplines of aerospace engineering. Several refinements to this process can come from following the "airplane criteria process" set out by Fulford. ${ }^{19}$ This shows how to establish requirements based on customer wishes, in a "criteria-driven, top-down" activity. As usage of the internet has become integral to learning, the wealth of documents available from NASA and industry enable students to develop much more relevant conceptual designs at an early stage. 
Synergy Between Aeronautical and Space Flight Concepts

In the 1990s, aerospace schools struggled with the debate between a single, generalized curriculum and offering specialization at the undergraduate level in aeronautics versus astronautics. The solution was to teach, starting in the freshman year, the commonality in design and analysis philosophy between aircraft and space vehicles. In this respect, academia both lead and lag industry. The typical aerospace engineer today has to be prepared to move frequently between projects involving aircraft and space vehicles. Inside a given corporation, however, there is little interaction between the "aircraft side" and the "space side", and their practices and "cultures" are quite different. For example, material developers for high-speed aircraft are often widely separated from their counterparts developing space vehicles.

\section{Better Vertical Integration}

A huge problem is the difficulty encountered by students in "remembering" and applying what they learned in previous courses, in follow-on courses. This problem is being attacked using integrative projects, combining computer power, internet access and industry experience to allow students to work on much more "real-life" problems within the constraints of time. ${ }^{20}$ Since 1989, a course has been in place at Penn State in which students design, build and fly sailplanes. ${ }^{21}$ This course is integrated vertically across academic years, horizontally across disciplines. It involves students at all levels in a continuing team effort that has immediate relevance to the needs of modern industry. This then provides an excellent means to introduce sophisticated analysis and design tools into the curriculum.

\section{Bolder Use of Applied Mathematics}

A powerful lesson learned from watching the best in industry operate is that they use applied mathematics to an exhilarating extent - they are able to get many of the answers to very difficult design problems through the clever use of mathematics. Injecting more mathematics into the curriculum goes against the trend of "dumbing down" the mathematics content of curricula, but nevertheless, seems to be the more sensible approach. The engineer of 2016 must come out with vastly better confidence and tools in mathematics than predecessors from 20 years earlier.

\section{Change from "Costing" to "Business Case" Projections}

We were urged during our time with Boeing to include "costing" in engineering courses. Observation however, suggests that the real need is not so much for engineers to understand "cost" as to be able to make the business case for their ideas. The current system is to expect engineers to work out the costs - then "throw the idea over the wall" to the accountants and marketing experts to figure out if the company can make money with the idea. The catch here is that these experts lack the technical depth, breadth and imagination to serve as effective advocates for really new ideas or for that matter, to understand how a technical idea can be "adjusted" to improve profitability. The result is that they get "market projections" based on yesterday's "realities", unaware of the opportunities for completely new realities. Since it is hard to visualize marketers learning engineering, the apparent solution to this is for engineers themselves to learn enough about "business case projection" to incorporate their technical knowledge and imagination and articulate the possible realities as part of the business case.

A simple example might illustrate this case. People naturally ask, "How much will this cost?" The real issue is. "How much money can we make?" which leads to a completely different 
projection. For example, a pizza delivered to Earth orbit would cost $\$ 50,000$, but so does any other food there - and if humans must stay up there, the business case for pizza delivery may not be bad. The cost of a roundtrip economy class airline ticket from Asia to the US is higher than the average annual income of many communities there - thereby "proving" that there is no conceivable market for air travel from Asia. This is laughable today, but that is simply because people eventually figured out the business case - customers saw the opportunities opened up by this vastly "expensive" business. It takes an imaginative and persistent engineer to reason this out at the conceptual design stage - it should not be left solely to the accountants.

\section{The "Knowledge Pyramid" and Related Issues}

Spitzer $^{21}$ used the knowledge pyramid to articulate the Boeing vision on the evolving role of engineers. To develop the products of the future technological marketplace, engineers must move ever higher on this pyramid. Along with curricular efforts to integrate knowledge, the university environment must seek ways by which students can gain the experience of bringing multifaceted projects to successful completion under realistic workplace constraints.

Knowledge management $(\mathrm{KM})$ techniques ${ }^{22,23,24,25}$ are being recognized as key to improved competitiveness in industry. In situations where the capture and integration of the relevant knowledge is more important than its subsequent management, knowledge integration is a more relevant descriptor of this process. "KI/ KM" in this sense refers to principles and techniques which enable retention, sharing and systematic application of critical knowledge across geographic and temporal expanses.

Starting in the mid-90s, KI principles were applied at Georgia Tech to enable large team projects that were until then impractical to attempt with undergraduate student team members in a research environment. We sought to take our developments in flow diagnostic techniques, and other research experiments, to unique facilities located away from the university. The experience of five such successful projects is described in a paper presented to the ASEE in $2001 .^{26}$ The Penn State sailplane design-build-fly course demonstrates knowledge retention, transfer and application, refining the design every year. ${ }^{21}$

\section{Learning Across Disciplines: Approach to Knowledge Capture, Transfer and Retention}

While industry worries about capturing the knowledge of veteran experts before they retire, universities should address the other side of that issue: readying recipients for such knowledge transfer. This demands excellent vertical and horizontal integration, starting the engineer in a culture of learning swiftly from diverse sources and using imagination and homework to substitute for years of experience. The Aerospace Digital Library initiative ${ }^{27}$ based at Georgia Tech is based on the following line of thought: to work at the leading edge of technology, the engineer must be able to absorb and integrate knowledge from many disciplines and from all over the world. Conceptual design provides perspective through a learner-centered gateway, which accepts users at any level. Sequential course material presents the discipline rigorously and logically, with concept engines and examples cross-linking subject areas. Simple introductions to undergraduate-level content and guidance to related areas are the most popular resources for users worldwide. The website is built around a freshman-level introduction to aerospace engineering and links to courses and other resources at all levels. This mechanism gets students used to the idea of seamless browsing across disciplines and levels, while encountering 
material at uncompromising depth on technical disciplines. Initial misgivings about the formidable task of linking across disciplines proved groundless as learners became skilled with the evolving search engines. User intelligence and experience augmented the tool's capabilities.

\section{Innovation in an Age of Optimal Systems}

The ideas and resources above provide the tool-kit and support systems for innovation - but innovation itself is the key to leadership. How do good ideas turn into successful products or technologies in today's environment and beyond? Some good insights into the process of innovation come from Hargaddon, ${ }^{28}$ who argues that this process depends to a high degree on the presence of networks, of dynamic interaction between people in different fields of endeavor, and "working in a number of outside worlds". It also comes from a culture of constantly thinking across rather than along traditional disciplines. Some important practices to help stimulate innovation are noted in Table 3 .

On the one hand, innovation today should be much easier. The internet enables people anywhere to investigate and learn about innovations, practices, and technologies everywhere. Communication is fast: the process of searching for past work takes a few minutes rather than days. In addition the tools to evaluate the system impact of a new technology is readily available, down to simulation and optimization of the full lifecycle. Bridging otherwise disconnected worlds should be quick and easy. On the other hand, the human element of this process is difficult. In large corporations, well-organized work-teams often pursue certain avenues of development, impervious to other developments. In

Table 3: Some important work practices for innovation $\operatorname{are}^{28}$

- Capturing good ideas

- Keeping ideas alive

- Imagining new uses for old ideas

- Putting promising concept to the test

- A culture of asking for help

- Failing your way to success

an intense world of project deadlines, there is no time for peripheral interests. Hargadon ${ }^{28}$ cites the saying "If only HP knew what HP knows" and points out that it is generally applicable to most large companies. "Organizations are their own fragmented landscapes, broken into the many small worlds of their divisions, groups and teams".

Surprisingly, the tools for system lifecycle simulation and optimization also hinder innovation to a significant extent. Since these tools are not yet mature. It takes a lot of time and expertise to get an answer using them - and yet, no innovation is allowed to progress unless it passes approval by these tools. Using these tools is beyond the resources of most engineers, and hence their ideas languish for lack of avenues where they can be explored. The downsizing of research efforts by most companies aggravates this problem.

\section{Teamwork}

Working in and across teams is an integral part of the modern workplace. Teamwork is difficult in a "Totem" environment of job insecurity. One issue is the disconnect between the needs of the team and the reward system for the individual. The winners of the future will be able to make their employees feel secure and wanted. They will align avenues for personal advancement with the long-term interests of the company, thus freeing employees to focus $100 \%$ on working for the company. Part of the challenge here is in clearly communicating to employees the real strategic plans of the company and their implications for future careers. Winning in the competitive 
workplace requires empowering employees. As the workforce shrinks and employees are asked to participate in many tasks, giving people the skills and training to handle multitasking appears to be an essential part of management. In the winning workplaces of the future, one expects to see a continual improvement in the ease with which people work together without having to fit into any particular "culture", so that they can each perform at their very best. Students must be educated carefully in this respect.

\section{The Debate Over Systems Engineering}

In the late 90 s and early 2000s, industry emphasized the need for systems thinking, and the demand for systems engineers. This led to an examination by university faculty of how to respond to this demand. Several ideas are advanced. One holds that students graduating with aerospace engineering degrees from modern programs, are already equipped very well with the "desired attributes of the engineer". After all, these are integral to the accreditation criteria for those programs. This view further holds that aerospace engineering is the ultimate "systems engineering" field, where students acquire technical depth as well as the skill to work across disciplines. McMasters and Cummings ${ }^{14}$ opined: "Aerospace engineering remains the single institutionalized multidisciplinary large-scale systems-oriented program in our current engineering education system". At the same time, they also recognized the "need for students to understand the unity of the fundamental tools and concepts needed for engineering practice rather than providing them a vast bag of tricks for solving selected problems".

Another idea is that there are three very different types of "systems engineers" sought by industry - and rarely if ever would the same people fit all three descriptions: systems architect, systems analyst and systems integrator. To this we add "system designer" - which in its present realization, fits somewhere between analyst and integrator, but does not quite get to the architect level. Others ${ }^{29}$ argue that systems engineering as a field is becoming much more detached from its "domain dependence" and is an as yet unappreciated new discipline with increasing depth. They point out that today systems engineering is attached to other disciplines in school descriptions. As "domain dependence" decreases, newer theories and different ways of looking at system architectures may develop, revolutionizing engineering. Today's discipline domains may come to be seen as technology skill areas.

\section{Conclusions}

In this paper, we have tried to lay out some implications of present trends in the aerospace industry. We hope that the opportunities opened by large-system integration and lifecycle simulation capabilities, will move the industry to a new level with expanded markets and grand challenges. This is the marketplace for which we must tailor the education of the future engineer so that the traditions of innovation leadership continue to flourish.

\section{Authors' Note}

This is Paper No. 2005-0879 at the 2005 ASEE Conference and Exposition in Portland, Oregon, June 2005. Much of the discussion for this paper was done in the summer of 2004 while the authors were Boeing Welliver Fellows. We gratefully acknowledge the support of the Boeing company in enabling such discussions, but note that the opinions and interpretations expressed here are our own, and not to be attributed to the Boeing company. 


\section{References}

${ }^{1}$ Clough, W. et al., National Academy of Engineering, "The Engineer of 2020: Visions of Engineering in the New Century". National Academy Press, 2004, ISBN 0-309-53065-2, 118pp http://books.nap.edu/catalog/10999.html?onpi_newsdoc05172003

2 Campbell, Colin J., "Oil and Gas Liquids 2004 Scenario", Uppsala Hydrocarbon Depletion Study Group. Association for the Study of Peak Oil. http://www.peakoil.net/uhdsg/Default.htm

3 Liu, E., "Large Scale Wind Hydrogen Systems". General Electric Corporation, Global Research Division, September 2003.

${ }^{4}$ Mott, Michael, "Opening Remarks to the Aldridge Commission". Testimony to the President's Commission on Implementation of U.S. Space Exploration Policy, Dayton, Ohio, March 4, 2004.

5 Mercer, Ilana, Bye-bye engineering, hello massage therapy, 2004 WorldNetDaily.com, April 16, 2004 http://www.worldnetdaily.com/news/article.asp?ARTICLE_ID=38064

6 'Exporting' High-Tech Jobs: Part I http://www.wnd.com/news/article.asp?ARTICLE_ID=36098

7 Segal, A., "Is America Losing Its Edge?” Foreign Affairs, November/December $200 \overline{4}$.

${ }^{8}$ Miller, Richard K., "IT Outsourcing Need Not Threaten Our Future” Engineering Trends, May 2004 http://www.engtrends.com/edit 05-2004.html

${ }^{9}$ Williams, James C., "Technology and Engineering in the American Experience: A Survey of Literature"

${ }^{10}$ The American Engineering Campaign: The Future Begins With Engineers". http://www.Greatachievements.org

${ }^{11}$ Segal, A., "Is America Losing Its Edge?" Foreign Affairs, November-December 2004

${ }^{12}$ Collins, P., "Space Hotels - Civil Engineering's New Frontier", Journal of Aerospace Engineering, ASCE, Vol 15, no 1, pp 10-19. http://www.spacefuture.com/archive/space hotels civil engineerings new frontier.shtml

${ }^{13}$ Armstrong, Spence M., "High Speed Research Lessons”. Report To The NASA Advisory Council. Aug. '99 14 McMasters, John H., Cummings, R. M., "Those Who Have Imagination Without Learning Have Wings But No Feet - Early 21st Century Challenges for Aerospace and Engineering Education” Invited by Tau Beta Pi national engineering honor society, May 2004.

15 The Boeing Co., "Desired Attributes of an Engineer" http://www.boeing.com/companyoffices/pwu/attributes/attributes.html

${ }^{16}$ Barke, R., Lane, E.O., Knoespel, K., "Shaping The Future of American University Education, or What Does it Mean to Call Engineering a Liberal Art?" 4th POSTI International Conference, "Europe's 21. century policies for sustainable technological innovation: The role of higher education in science, technology and society," Oslo, Norway, 20-21 May, 2001

${ }^{17}$ Felder, R.M., Woods, D.R., Stice, J.E., Rugarcia, A., "The Future Of Engineering Education II. Teaching Methods That Work" Chem. Engr. Education, 34(1), 26-39 (2000).

${ }^{18}$ Komerath, N.M., "Design Centered Introduction: 3-Year Experience With the Gateway to the Aerospace Digital Library". Session 2225, Proceedings of the ASEE Annual Conference, St. Louis, MO, June 2000

19 Fulford, Robert H., “Airplane Criteria Process". Paper 975567, SAE World Aviation Congress, Anaheim, CA, Oct, 97.

${ }^{20}$ Smith, M.J., Komerath, N.M., "The Virtual Laboratory: Technology Enhancement for Engineering Education", Proceedings of the ASEE Annual Conference, Albuquerque, NM, June 2001 http://www.adl.gatech.edu/archives/adlp01062701.pdf

${ }^{21}$ Bramesfeld, G. and Maughmer, M.D., "The Penn State Sailplane Project - The First Decade," (Invited), AIAA Applied Aerodynamics Conference, St. Louis, MO, June 24-27, 2002, AIAA 2002-2723.

${ }^{21}$ Spitzer, R., Boeing Perspective on Future Transportation Systems for America. IUGREEE Knowledge Management Workshop and Business Meeting, Cleveland, OH Oct, 2000. http://www.oai.org/IUGREEE-KM/index.html

${ }^{22}$ Anon, White Paper on Knowledge Management, "White_Paper_KM_thrust.PDF”, Industry- University- Government Roundtable on Enhancement of Engineering Education. http:// www.oai.edu

${ }^{23}$ Matsch, L., Melsa, J., "Ties Among Knowledge Management, Engineering Practice in Industry, and Engineering Education”. IUGREEE Working Paper, September 1998.”. Journal of Universal Computer Science, Vol. 3, No. 8. , 1997.

${ }^{24}$ Nonaka, I., Takeuchi, H., "The Knowledge-Creating Company”, Oxford University Press, 1995.

${ }^{25}$ Milton, N., "Mining the Deep Knowledge: Tapping Into Things You Don't Know You Know”. Knowledge Transformation International, 1999. From http://www.oai.edu

${ }^{26}$ Komerath, N.M., "Knowledge Management Techniques in Experimental Projects". ASEE Annual Conference and Exposition, Session 1426, June 2001. Aerospace Digital Library, Paper No. adlp01062602.pdf http://www.adl.gatech.edu/archives/

${ }^{27}$ Komerath, N.M., Smith, M.J., "Lessons Learned from a Resource for Learning Across Disciplines". Chap. 13. In Aung, W., Hoffman, M., King, R., Ng, W.J., Sanchez Ruiz, L.M., Editors, "INNOVATIONS 2003: World Innovations in Engineering Education and Research". INEER, Arlington, VA. Library of Congress T65.3.I55 2003

${ }^{28}$ Hargadon, A., "How Breakthroughs Happen: The Surprising Truth About How Companies Innovate". Harvard Business School Press, 2003.

${ }^{33}$ Professor Peter Freeman, Welliver Fellowship report presentation to the Boeing company, August 2004.

\section{Proceedings of the 2005 American Society for Engineering Education Annual Conference \& Exposition} Copyright ASEE 2005, American Society for Engineering Education. 


\section{Biographies}

Dr. Narayanan Komerath is a Professor of Aerospace Engineering at Georgia Institute of Technology, Atlanta, USA. He is a Fellow of the NASA Institute of Advanced Concepts (NIAC), Associate Fellow of the AIAA.

Currently he holds a Senior Nunn Security Fellowship at the Center for Strategy, Technology and Policy Issues and a Hesburgh Senior Teaching Fellowship at the Center for Excellence in Teaching and Learning at Georgia Tech. He spent the summer of 2004 as an A.D. Welliver Faculty Fellow at the Boeing company.

Dr. Mark D. Maughmer is a Professor of Aerospace Engineering at The Pennsylvania State University, University Park, PA.. He received his B.S. and PhD in Aeronautical and Astronautical Engineering from the University of Illinois, and an M.S. in Aerospace and Mechanical Sciences from Princeton University. His areas of teaching and research involve analytical, computational and experimental aerodynamics, including aircraft design, performance, stability and control, airfoil design and analysis, and low-Reynolds number aerodynamics. He is an Associate Fellow of the American Institute of Aeronautics and Astronautics. In 1993 and 2001, respectively, he received the Penn State Engineering Society Outstanding Teaching Award and Premiere Teaching Award. He spent the summer of 2004 as an A.D. Welliver Faculty Fellow at the Boeing Company. 